\title{
PERBEDAAN PANJANG TUNGKAI (LEG LENGTH DISCREPANCY) \\ DALAM ORTHOPAEDI \\ Bambang Widiwanto*
}

\begin{abstract}
ABSTRAK
Masalah leg length discrepancy dalam orthopaedi bukan hanya permasalahan kosmetik, tetapi juga permasalahan fungsional. Ada empat jenis terapi yang memungkinkan untuk menyeimbangkan panjang tungkai : (1) sepatu tambahan atau konversi dengan prostetik (2) epiphysiodesis pada sisi tungkai yang panjang (3) pemendekan pada sisi tungkai yang panjang (4) pemanjangan pada sisi tungkai yang pendek. Kombinasi antara pemanjangan pada ipsilateral dan epiphysiodesis pada kontralateral dapat digunakan pada ketidaksamaan yang bermakna untuk mengurangi jumlah pemanjangan yang dibutubkan. (Champbell,2007)

Semua tipe alat dan teknik pemanjangan tungkai memiliki komplikasi. (1) Pin Track Infection (2) berhubungan dengan otot, terjadi Flexion contracture (3) Subluksasil dislokasi sendi (4) infeksi, pseudoarthrosis, plate patah dan malunion. (Stanitski,1999)
\end{abstract}

Keywords : Leg length discrepancy, terapi, komplikasi.

\section{LEG LENGTH DISCREPANCY IN THE ORTHOPAEDIC Bambang Widiwanto*}

\begin{abstract}
Leg length discrepancy in the orthopaedic is not only a cosmetic concern but also a functional concern. Four types of treatment are available for limb-length equalization (1) shoe lift or prosthetic conversion (2) epiphysiodesis of the long leg (3) shortening of the long leg (4) lengthening of the short leg. Judicious combinations of ipsilateral lengthening and contralateral epiphysiodesis can be used for significant discrepancies to reduce the amount of lengthening required. (Champbell,2007)

All types of limb-lengthening devices and techniques have some complications in common (1) pin track infection (2) Disturbance with muscle can happen like flexion contracture(3) Subluxation/dislocation of joint (4) infection, pseudoartrosis, broken plate and malunion. (Stanitski,1999)
\end{abstract}

Keywords : Leg length discrepancy, treatment, complications.

\footnotetext{
* Staff Pengajar Fakultas Kedokteran

Universitas Mubammadiyah Malang
} 


\section{A. PENDAHULUAN}

Masalah leg length discrepancy (LLD) dalam orthopaedi bukan hanya permasalahan kosmetik, tetapi juga permasalahan fungsional. Gait dari tungkai yang pendek menimbulkan kejanggalan dan meningkatkan kebutuhan energi dikarenakan pergerakan vertical pelvis yang naik turun secara berlebihan dan dapat menimbulkan nyeri punggung akibat ketidaksesuaian panjang dari kedua ekstremitas saat berdiri lama.

Dalam suatu studi dari 23 orang dewasa muda dengan LLD 1,2 - 5,2 cm yang tidak dikoreksi, didapatkan skoliosis kompensasi dan penurunan mobilitas tulang belakang, tanpa disertai nyeri punggung.(Papaioannou,1982) Giles, taylor dan Friberg mempelajari pasien dengan jumlah yang lebih besar dan menyimpuklan bahwa LLD yang signifikan menyebabkan nyeri pungung bawah, dan nyeri berkurang dengan menyamakan panjang tungkai.(Giles,1981)

Ketidaksamaan panjang tungkai dapat disebabkan oleh trauma atau infeksi yang merusak physis dari kondisi paralisis yang asimetris (seperti poliomyelitis atau cerebral palsy) atau dari tumor atau keadaan yang menyerupai tumor (tumor-like) yang mempengaruhi pertumbuhan tulang dengan menstimulasi pertumbuhan yang asimetris, seperti terjadi pada juvenile rheumatoid arthritis atau post fracture bypervascularity. Idiopathic unilateral bypoplasia dan idiopatbic unilateral byperplasia adalah penyebab LLD lainnya yang terbanyak.(Champbell,2007)

Pengobatan LLD harus disesuaikan dengan kondisi khusus dan membutuhkan kesabaran individu. Rencana pengobatan dapat dirancang setelah evaluasi yang teliti termasuk pemeriksaan yang berturut-turut dan usia tulang dari pasien, ketidaksesuaian panjang tungkai saat ini dan panjang tungkai prediksi, prediksi tinggi badan dewasa, penyebab ketidaksesuaian, status fungsional dari sendi dan latarbelakang sosial dan psikologis dari pasien dan keluarga pasien. (Champbell,2007)

Ada empat jenis pengobatan yang memungkinkan untuk menyeimbangkan panjang tungkai : (1) sepatu tambahan atau konversi dengan prostetik (2) epiphysiodesis pada sisi tungkai yang panjang (3) pemendekan pada sisi tungkai yang panjang (dilakukan pada pasien yang sangat tua untuk dilakukan epiphysiodesis) dan (4) pemanjangan pada sisi tungkai yang pendek. Kombinasi antara pemanjangan pada ipsilateral dan epiphysiodesis pada kontralateral dapat digunakan pada ketidaksamaan yang bermakna untuk mengurangi jumlah pemanjangan yang dibutuhkan. (Champbell,2007)

Pemendekan memiliki beberepa kerugian : (1) tungkai normal menjalani operasi lebih banyak dibandingkan tungkai yang sakit, dan jika ada kelainan pada tungkai yang pendek, dibutuhkan operasi kedua untuk mengkoreksi kelainan tersebut, (2) menghasilkan proporsi tubuh yang secara kosmetik tidak nyaman setelah pemendekan, (3) derajat pemendekan yang mungkin dilakukan terbatas karena ketidakmampuan otot untuk beradaptasi terhadap pemendekan $>5 \mathrm{~cm}$, dan (4) tinggi akhir setelah pemendekan adalah pendek atau epiphysiodesis unacceptably low. (Champbell,2007)

Program pemanjangan tungkai membutuhkan komitmen penuh dari pasien dan keluarga pasien untuk berpartisipasi maksimal. Kesuksesan pemanjangan tungkai tergantung pada usaha pasien pada terapi fisik dan perawatan eksternal fiksasi. Pasien yang tidak mampu berpartisipasi dalam follow up yang sering atau tidak memiliki dukungan perawatan eksternal fiksasi dengan baik maupun terapi fisik lebih baik diobati dengan cara lain selain pemanjangan tungkai. (Champbell,2007)

Semua tipe alat dan teknik pemanjangan tungkai memiliki komplikasi. (1) Pin Track Infection (2) berhubungan dengan otot, terjadi Flexion contracture (3) Subluksasi/ dislokasi sendi dilaporkan selama pemanjangan (4) infeksi, pseudoarthrosis, plate patah dan malunion.(Champbell,2007)

\section{B. LEG LENGTH DISCREPANCY}

Leg length discrepancy disebabkan oleh dua type proses. Proses pertama karena perubahan panjang kaki langsung dan proses kedua karena perubahan proses pertumbuhan. (Morissy, 2006)

Pertumbuhan dari physis dapat melambat karena tiga mekanisme. Pertama congenital short bones tumbuh lebih lambat dibandingkan dengan yang normal dikarenakan program yang abnormal dari mekanisme genetic growth rate. Kedua growth plate dapat mengalami injuri sehingga sebagian atau seluruh bagian tidak dapat tumbuh. Ketiga perubahan lingkungan yang terjadi yang terjadi pada growth plate dapat menyebabkan gangguan pertumbuhan. (Morissy, 2006) 


\section{B.1 Penyebab Leg length discrepancy B.1.1 Congenital shortening}

Ketika pasien lahir dengan kaki yang tidak sama panjang dengan yang normal, sering tidak diketahui yang mana mengalami abnormal. Pemendekan tulang kongenital sering menunjukkan perubahan kualitatif seperti halnya kuantitatif. Pemendekan femur kongenital dapat ditandai dengan coxa vara, bowing, hipoplasia kondilus lateralis dan eksternal rotasi. Hal ini bisa berkaitan dengan insufisiensi ligament crusiate anterior, pemendekan atau hilangnya fibula. (Morissy, 2006)

\section{B.1.2 Trauma}

Trauma pada physeal plate dapat memperlambat pertumbuhan baik injuri langsung terhadap sel yang bertanggung jawab terhadap pertumbuhan atau terhadap formasi jembatan tulang antara epifisis ke metafisis.(Solomon,2001) Kombinasi pemendekan dan pembengkokan biasanya terjadi pada tahun pertama setelah fraktur. Jembatan tulang yang menyebabkan gangguan pertumbuhan dapat dieksisi jika frakturnya kecil dan perifer. (Morissy, 2006)

\section{B.1.3 Infeksi}

Osteomyelitis pada plate dapat menyebabkan destruksi sel-sel physis dan mengganggu pertumbuhan biasanya tidak memerlukan terapi awal. Infeksi biasanya hematogen osteomyelitis pada metafisis, tetapi bisa mencapai epifisis pada anak-anak dan dapat diikuti oleh septic arthritis. Jembatan tulang yang terbentuk akibat infeksi lebih sulit diatasi dibanding akibat trauma. (Morissy, 2006)

\section{B.1.4 Paralysis}

Hambatan dari pertumbuhan sering berhubungan dengan kelemahan atau paralysis dari kaki tetapi mekanisme inhibisi masih belum jelas. Kemungkinan terjadi penurunan aliran darah dikarenakan berkurangnya massa otot namun tidak berarti aliran ke physis juga berkurang. Venous return yang sebagian berasal dari aktivitas otot sehingga penurunan aktivitas otot dan penurunan dari efek pumping dapat menurunkan aliran kepada ekstremitas dan kemungkinan juga pada physis. Pada kasus cerebral palsy, perbedaan panjang kaki dapat diatasi dengan stimulasi physis untuk tumbuh sesuai dengan hukum Heuter-Volkman. (Morissy, 2006)

\section{B.1.5 Tumor}

Leg Length Discrepancy dapat disebabkan oleh tumor melalui beberapa cara. Yaitu destruksi pada physis karena invasi tumor, irradiasi yang digunakan sebagai terapi tumor dan diversi kartilago physis menjadi tumor sehingga menghambat pertumbuhan physis. (Morissy, 2006)

\section{B.1.6 Avascular Necrosis}

Karena sirkulasi dari physis berasal dari sirkulasi epiphyseal, avascular necrosis dari epiphysis sering melibatkan growth plate sehingga menyebabkan leg length discrepancy. Hal ini terjadi pada kasus LeggPerthes dan DDH. (Morissy, 2006)

\section{TERAPI}

Ada empat jenis terapi yang memungkinkan untuk menyeimbangkan panjang tungkai (1) sepatu tambahan atau konversi dengan prostetik epiphysiodesis pada sisi tungkai yang panjang (3) pemendekan pada sisi tungkai yang panjang (dilakukan pada pasien yang sangat tua untuk dilakukan epiphysiodesis) dan (4) pemanjangan pada sisi tungkai yang pendek. Kombinasi antara pemanjangan pada ipsilateral dan epiphysiodesis pada kontralateral dapat digunakan pada ketidaksamaan yang bermakna untuk mengurangi jumlah pemanjangan yang dibutuhkan.(Campbell,2007)

Untuk ketidaksamaan yang ringan yaitu d" $1,5 \mathrm{~cm}$, tidak memerlukan pengobatan. Jika pasien memiliki keinginan untuk dikoreksi, penggunaan tambalan sepatu $1 \mathrm{~cm}$ dapat ditambahkan pada bagian dalam sepatu yang dipakai. Kenaikan yang dibutuhkan tidak mengimbangi keseluruhan ketidaksamaan karena orang-orang jarang berdiri tegak dengan kedua lutut dan pinggang dalam keadaan lurus, kebanyakan orang memilliki perbedaan kecil $(1 \mathrm{~cm})$ yang secara fungsi tidak bermakna. (Campbell,2007)

Derajat ketidaksamaan yang dapat dikompensasi dengan tambalan sepatu pada bagian dalam sangat terbatas, tetapi untuk perbedaan 2 $4 \mathrm{~cm}$ tambalan pada sisi luar dari sepatu dibutuhkan, meskipun itu dapat meruncing ke bagian depan 
sepatu. Untuk perbedaan yang kecil, tambalan pada tumit dapat digunakan dan untuk perbedaan yang lebih besar, diperlukan tambalan penuh pada seluruh alas sepatu.

Untuk membatasi jumlah tambalan eksternal, pembuat sepatu dapat menipiskan tumit pada sepatu tinggi sekitar $1 \mathrm{~cm}$. Tambalan sepatu dapat digunakan pada pasien dengan perbedaan yang besar jika pasien menolak untuk dilakukan pemendekan atau pemanjangan. Tambalan $5-10$ $\mathrm{cm}$ tidak enak dipandang dan tidak stabil dan membutuhkan tambahan tegak lurus atau ankle-foot orthosis untuk menyokong pergelangan kaki. (Campbell,2007)

Banyak anak-anak yang menolak untuk menggunakan tambalan sepatu menjelang remaja, mereka malah lebih menyukai berjalan dengan mekanisme kompensasi, termasuk ankle equines, pelvis miring dan fleksi lutut kontralateral. Penambahan prosthesis berupa tambalan sepatu yang dimodifikasi pada kaki yang tidak diamputasi. Malahan kaki dipaksa ke dalam posisi equinus dan dicocokkan dengan protesis tertentu yang merupakan protesis kaki bagian distal pada kaki normal. Konversi dengan Syme/ Boyd amputasi lebih disukai untuk mempermudah mencocokkan protesis. (Campbell,2007)

\section{OPERASI}

Secara teoritis, pemanjangan kaki yang pendek merupakan pengobatan optimal, tetapi secara teknik sulit sering menimbulkan komplikasi sehingga epiphysiodesis menjadi pilihan yang lebih menarik untuk ketidaksamaan yang ringan. Pada anak yang sedang tumbuh, epiphysiodesis adalah prosedur yang relative sederhana dengan alasan morbiditas yang rendah dan penyembuhan yang cepat. Pada remaja lanjut untuk epiphysiodesis yang efektif, pemendekan tungkai akurat, aman dan simple, dengan rata-rata komplikasi sedikit lebih tinggi daripada epiphysiodesis. Kekakuan sendi setelah pemendekan jarang dijumpai karena otot dibuat kendur dengan pemendekan tungkai, sebaliknya pada pemanjangan tungkai, sering terjadi kekakuan sendi yang menetap dan subluksasi. (Campbell,2007)

Pemendekan memiliki beberepa kerugian : (1) tungkai normal menjalani operasi lebih banyak dibandingkan tungkai yang sakit, dan jika ada kelainan pada tungkai yang pendek, dibutuhkan operasi kedua untuk mengkoreksi kelainan tersebut,(2) menghasilkan proporsi tubuh yang secara kosmetik tidak nyaman setelah pemendekan, (3) derajat pemendekan yang mungkin dilakukan terbatas karena ketidakmampuan otot untuk beradaptasi terhadap pemendekan $>5 \mathrm{~cm}$, dan (4) tinggi akhir setelah pemendekan atau epiphysiodesis hasilnya pendek. (Stanitski ,1999)

Dalam penulisan ini yang dibahas hanya pemanjangan tungkai (limb lengthening).

\section{D.1 Limb lengthening}

Program pemanjangan tungkai membutuhkan komitmen penuh dari pasien dan keluarga pasien untuk berpartisipasi maksimal. Kesuksesan pemanjangan tungkai tergantung pada usaha pasien pada terapi fisik dan perawatan eksternal fiksasi. Acute long bone lengthening jarang diindikasikan, tetapi Salter memperkenalkan acute distraction dan interposition grafting melalui innominate bone. (Campbell,2007)

Millis and Hall melaporkan modifikasi teknik ini dengan rata-rata pemanjangan $2,3 \mathrm{~cm}$ pada 20 pasien dengan acetabular dysplasia disertai pemendekan femur, ketidaksamaan panjang tungkai, skoliosis tidak terkompensasi, primary intrapelvic asymmetry. Teknik ini digunakan pada pasien yang membutuhkan rekonstruksi acetabulum, tetapi epiphysiodesis atau teknik gradual distraction lengthening lebih diandalkan sebagai alternative bagi isolated LLD.. (Millis,1979)

Osteotomi diikuti distraksi bertahap dari fragmen tulang dengan peralatan mekanik merupakan prosedur dasar dari pemanjangan tungkai sejak Putti melaporkan tekniknya pada tahun 1921. Osteotomi dan teknik fiksasi dimodifikasi oleh beberapa penulis, tetapi tingkat komplikasi dilaporkan pada semua metode, termasuk infeksi yang dalam, non union, fraktur setelah aff plate, malunion dan nerve palsy. (Campbell,2007)

Wagner memperkenalkan low-profile, mobile, monolateral fixator yang meningkatkan hasil, dan DeBastiani mendesain bentuk yang sama tetapi dengan fiksator yang lebih cakap (Orthofix). (De bastiani,1987)

Pada awal 1950, Ilizarov menemukan thinwire, circular external fixator untuk fiksasi fraktur dan menemukan bahwa distaksi perlahan dengan alat 
menyebabkan regenerasi tulang pada distraction gap. Untuk prosedur pemanjangan, dia menggunakan percutaneous "corticotomy" dengan korteks tulang panjang yang diakses dipotong $5 \mathrm{~mm}$ secara osteotomi melalui insisi kulit $10 \mathrm{~mm}$. untuk mmencegah penetrasi dari kanal medularis. (Campbell,2007)
Setelah 5-7 hari, distraktor mulai didistraksi $0,25 \mathrm{~mm} 4$ kali sehari. Thin wires $(1.8 \mathrm{~mm}$ or 1.5 $\mathrm{mm}$ ) ditegangkan sampai $130 \mathrm{~kg}$ untuk memberikan kekakuan tulang yang adekuat untuk stabilitas segmen tulang. Koreksi simultan atau sekuensi terhadap deformitas aksial, translasi dan rotasi. Pada anak fiksator dipakai kira-kira $1 \mathrm{~cm}$ per bulan untuk pemanjangan, dan pada dewasa $1 \mathrm{~cm}$ per 1,5 bulan. (Campbell,2007)
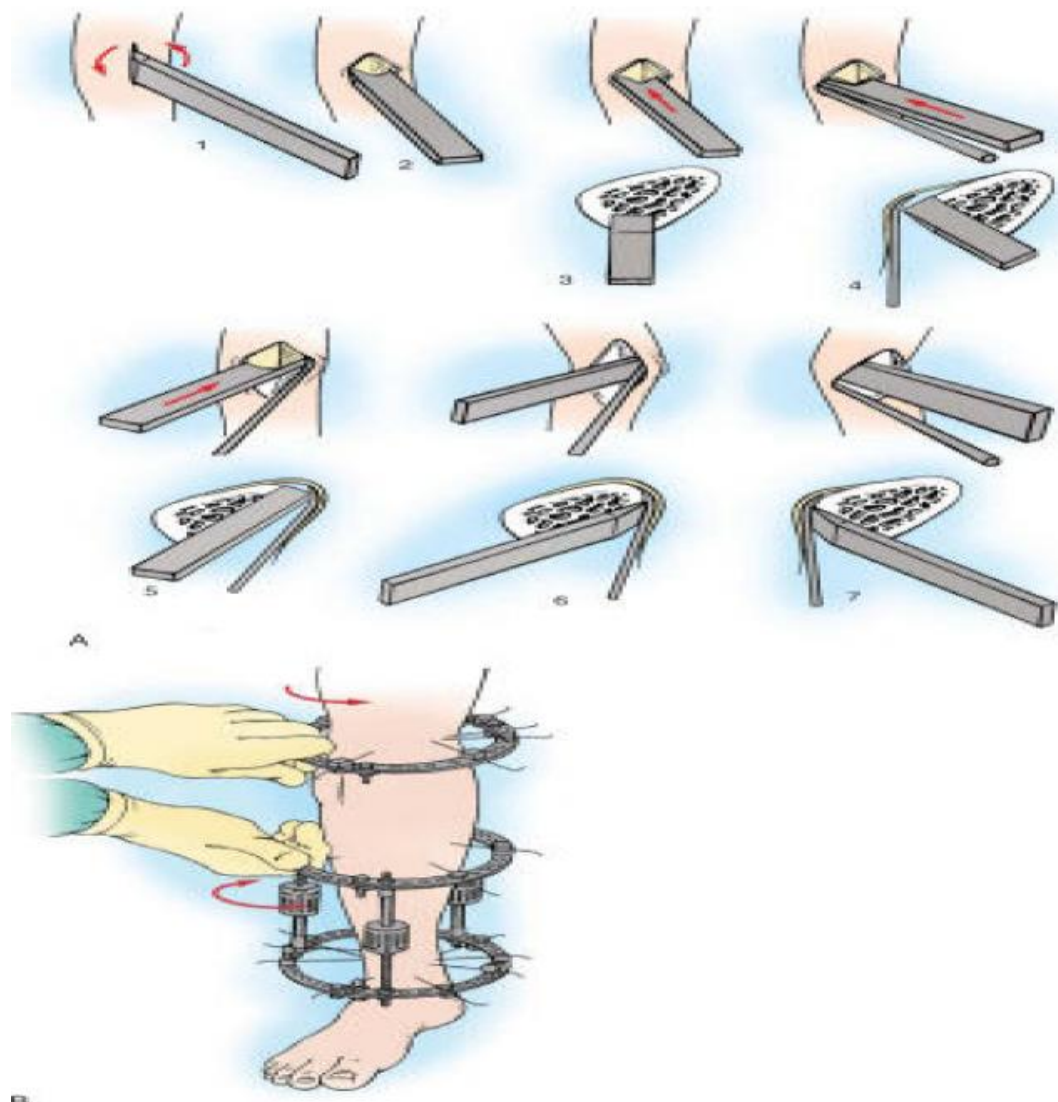

Percutaneo us tibial corticotomy, modified from Ilizarov. Entire tibia is cut through $1.5-\mathrm{cm}$ incision centered over a nte rior crest. Small elevator lifts periost eum on medial and lateral cortices; $5-\mathrm{mm}$ osteotome is used to cut first medial and then lateral cortex. Osteotome is reinserted in medial cortex and twisted 90 degrees to help fracture po sterior cortex. This maneuver is repeated along hateral cortex. B, If necessary, Ilizarov rings can be used to complete posterio $r$ aspect of corticotomy by exte mally rotating distal segment.

(Redrawn from Paley D, Catagni MA, Argnani F, et al: Ilizarov treatment of tibialnonunions with bone loss, Clin Orthop Relat Res 241:146, 1989.)

Gambar 1. Percutaneus tibial corticotomy modified from Illizarov (Paley,1989) 
Pemakaian fiksator dalam jangka waktu yang lama merupakan salah satu kerugian teknik Illizarov. Peralatan Illizarov dimodifikasi oleh Catagni dkk, yang mengganti semicircular ring dengan lengkungan 90 derajat dan 120 derajat yang memegang tulang dengan standar half-pins $5 \mathrm{~mm}$ atau $6 \mathrm{~mm}$. Green memodifikasi perlengkapan Illizarov dengan menggunakan half-pin fixation pada ring. The Taylor Spatial Frame

(Smith \& Nephew, Memphis, Tenn) secara simultan memanjangkan dan mengoreksi deformitas menggunakan computer-assisted application. (Campbell,2007)

Paley mengelompokkan komplikasi dari pemanjangan tungkai sebagai masalah, rintangan dan komplikasi. Problem seperti infeksi pin track dapat diatasi dengan perawatan poliklinis. Rintangan membutuhkan prosedur sekunder seperti repeat corticotomy, dan untuk konsolidasi permanen dari pemanjangan. Komplikasi adalah sekuel yang tidak diharapkan yang mempengaruhi hasil akhir. Komplikasi minor seperti residual equinus contracture, dan dioperasi untuk mendapatkan hasil yang lebih baik. Komplikasi mayor seperti permanent nerve palsy, sulit mendapat perbaikan walaupun dengan pembedahan. (Palley,1989)

Metode klasik Wagner dengan open osteotomy, melakukan diastasis segera dan pemanjangan 1 $\mathrm{mm}$ per hari diikuti dengan fiksasi oleh plate dan bone grafting. teknik terbaru dengan percutaneous corticotomy dan distraction osteogenesis merupakan suatu standar baru. Dua tipe dasar dari ekstrenal fiksasi yang cocok untuk pemanjangan tungkai setelah percutaneous corticotomy: half-pin monolateral devices yang besar dan circular devices yang dikombinasikan dengan wires dan half-pins. (Campbell,2007)

Monolateral devices relative simple untuk diaplikasikan, tetapi memiliki keterbatasan untuk mengoreksi kelainan angulasi dan rotasi dan tidak memiliki efek koreksi simultan dari kelainan yang kompleks. Wagner device yang original disetel hanya pada dua bidang, dan modifikasi Hoffman disetel dengan tambahan satu bidang lagi. (Huurman,1987)

DeBastiani's device (Orthofix) memiliki modular components yang memungkinkan untuk koreksi kelainan angulasi tertentu. Ilizarov device memiliki modular yang ekstrem dan dapat menyesuaikan dengan ekstensi dan engsel (hinges) untuk memanjangkan dan mengoreksi kelainan rotasi dan translasi secara simultan. Kelainan rotasi dapat dikoreksi pada saat pemasangan fiksator atau setelah aplikasi outriggers pada ring. (De bastiani,1987)

Yang terkini, Taylor Spatial Frame digunakan untuk koreksi deformitas dan pemanjangan. Frame ini menggunakan prinsip koreksi lambat dari system Iliozarov tetapi ditambahkan 6 aksis analisis deformitas yang disatukan dengan program computer. Fadel dan Hosny melaporkan penggunaan Taylor spatial frame untuk pemanjangan dan koreksi deformitas pada 22 pasien tungkai bawah (usia rata-rat 16.5 tahun). Dengan hasil 18 orang sempurna, 2 baik dan 2 sedang. (Campbell,2007)

Hasil dari Taylor Spatial Frame memang tidak sebaik Ilizarov external fixator, dan Taylor Spatial Frame membutuhkan biaya yang besar. (Campbell,2007)

Kristiansen dkk membandingkan 20 pemanjangan tibia dengan Taylor Spatial Frame dengan pemanjangan tibia dengan traditional Ilizarov external fixation. Tidak ditemukan perbedaan antara Taylor dan Ilizarov frames pada pola indek pemanjangan dan komplikasi, tetapi koreksi kelainan rotasi dan translasi lebih mudah dengan Taylor frame. (Kristiansen,2006)

Alat sirkuler lebih sulit untuk digunakan daripada monolateral fixators, dan perlu pelatihan lanjutan dan pengalaman sebelum menggunakannya. Pemanjangan alat internal dilakukan untuk mengeliminasi masalah yang berhubungan dengan infeksi pin track dan transfiksasi jaringan lunak untuk mempertahankan mechanical alignment dan stabilitas selama pemanjangan dan konsolidasi dan untuk memberikan kenyamanan pasien. (Campbell,2007)

Pemanjangan dari alat ini dimulai dengan rotasi yang melibatkan tungkai (Albizza nail; DePuy Australia Pty Ltd, Mount Waverly, Australia); rotasi terkontrol, ambulation, dan weight bearing (Intramedullary Skeletal Kinetic Device; Orthofix, McKinney, Tex); atau implanted electrically activated motorized drive (Fitbone; Wittenstein Igersheim, Germany). Saat ini, hanya Intramedullary Skeletal Kinetic Device (ISKDyang diakui oleh U.S. Food and Drug Administration.(Campbell,2007)

New Intramedullary Skeletal Kinetic Distractor (ISKD) (Orthofix, McKinney, Tex) 


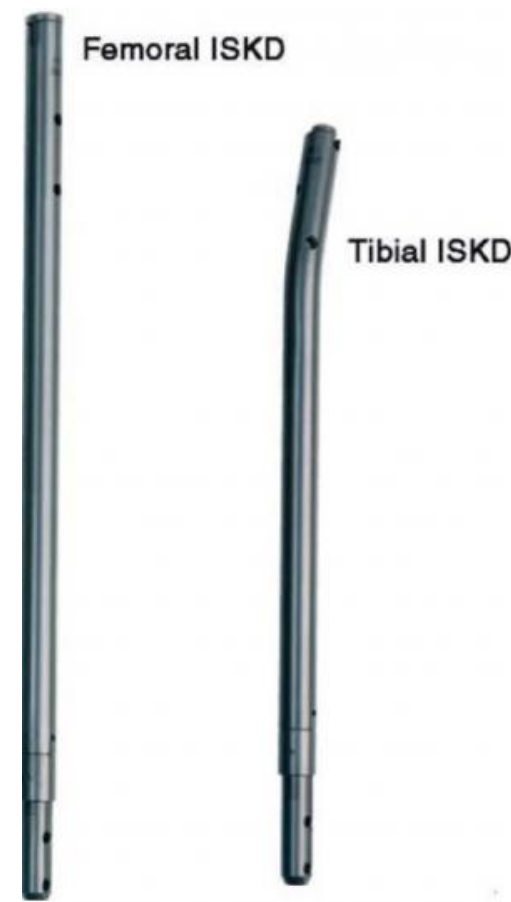

Gambar 2. New intramedulary skeletal kinetic distractor

\section{E. KOMPLIKASI OPERASI PEMANJANGAN (LIMB LEGTHENING)}

\section{E.1 Pin Track Infection}

Masalah tersering adalah infeksi pin track yang dapat diminimalisir dengan insersi pin yang hati-hati. Thin wires harus dimasukkan melalui kulit secara langsung pada level dimana wire masuk ke tulang untuk mencegah tenting kulit pada akhir prosedur, gerakkan sendi terdekat samapi pada ROM penuh lalu identifikasi tenting dari kulit, jika ada segera dibebaskan dengan pisau. (Stanitski ,1999)

Thin transfixion wires menyebabkan lebih sedikit masalah dibandingkan dengan large half-pins, tetapi pergerakan kulit dan otot diatas wire/pin harus diminimalisir dengan teknik dressing yang special. (Stanitski,1999)

Untuk thin-wire fixators, secara komersial tersedia 1 inchi kubus seperti busa dengan celah disekitar pin. Celah tersebut dijepret untuk menahan kubus tetap pada tempatnya.Dan clip atau perekat karet membalut kubus ke kulit dengan tekanan yang ringan . (Stanitski, 1999)
Tekanan yang berlebihan tidak boleh dilakukan karena dapat menyebabkan ulserasi , terutama pada tempat yang bony prominences. Untuk pin yang besar, terutama pada paha harus dibungkus dengan kasa steril mengelilingi 2 atau lebih pin dengan menekan kulit di sekitar pin. Semua perawatan wire dan pin harus dilakukan dengan steril dengan antiseptik seperti povidone iodine atau chlorhexidine glukonat tetapi hanya dalam jumlah sedikit $(1 \mathrm{ml} /$ pin) untuk mencegah iritasi kulit. Jika kulit mengalami iritasi maka bilas dengan cairan atau berikan antibiotika topical, seperti polymyxin B sulfate - neomycin sulfate.(Stanitski, 1999)

Pada awal terjadinya infeksi pin track, antibiotik spectrum luas harus diberikan, perawatan lokal terhadap pin harus lebih intensif dan jika perlu sisi pin dapat diinsisi untuk drainase. Jika infeksi tidak membaik dengan tindakan di atas, maka pin harus dicabut. Jika pencabutan pin membahayakan stabilitas dari frame, maka pin harus dimasukkan kembali. (Stanitski ,1999)

Dengan peralatan Illizarov, hal ini mudah dilakukan, wire dapat dimasukkan ke dekat lubang 
atau dijatuhkan ke bawah ring untuk mencegah infeksi sisi pin. Dengan fiksator monolateral, memasukkan pin pengganti jauh dari sisi pin yang terinfeksi lebih sulit dilakukan. Orthofix supplemental screw device dapat digunakan untuk memasukkan balf-pins tambahan. Infeksi yang berat biasanya memerlukan kuretase dari pin track dan tulang. (Stanitski ,1999)

\section{E.2 Masalah otot}

Komplikasi tersulit yang terjadi selama pemanjanagan berhubungan dengan otot. Secara teori, tulang dapat dipanjangkan seberapa panjangpun tetapi otot memiliki keterbatasan kemampuan untuk diregang. Secara tipikal, otot yang mengalami banyak masalah selama peregangan tibia adalah trisep surae dan selama peregangan femur adalah quadriceps femoris. (Stanitski ,1999)

Flexion contracture lutut sering terjadi selama pemanjangan tibia dan dapat dicegah dengan prophylactic splinting, terutama pada malam hari. Orthosis komersial yang ada seperti Dynasplints (Dynasplint Systems, Severna Park, Md) sangat membantu dan terapi fisik sangat penting untuk dirutinkan. (Stanitski, 1999)

Terapi profilaksis harus dimulai sejak 1 minggu setelah pembedahan. Untuk pemanjangan tibia $>4-5 \mathrm{~cm}$, kaki harus difiksasi dalam posisi netral dengan memberikan back slab (posterior plaster splint) sebagai fiksator monolateral atau dengan menempatkan dua wire pada tumit dan menghubungkannya dengan sebuah ring yang melekat pada frame dari thin-wire circular fixator. (Stanitski ,1999)

Pin pada tumit harus diambil sesegera mungkin setelah pemanjangan selesai/ komplit agar subtalar dan sendi pergelangan kaki bisa kembali bergerak. Pemanjangan tendon Achilles harus dipertimbangkan jika terjadi kontraktur yang menetap. Preoperatif kontraktur Achilles harus dikoreksi sebelum atau selama pemanjangan tibia. (Stanitski,1999)

\section{E.3 Masalah Sendi}

Subluksasi/ dislokasi sendi dilaporkan selama pemanjangan femur, terutama jika sendi pinggang dan lutut tidak stabil sebelum pembedahan. Pada pasien dengan kelainan kongenital, tenotomi profilaksis dari rectus femoris kearah proximal, adduktor dan terkadang hamstring dapat berguna. (Stanitski ,1999)

Untuk pinggang dengan kelainan varus, koreksi dengan valgus osteotomi ditunda sampai pemanjangan selesai. X-ray hip harus menunjukkan center-edge angle minimal 15 to 20 derajat sebelum pemanjangan femoral. Pelvic osteotomy mungkin dibutuhkan. Defisiensi ligament crusiatum pada pasien PFFD akan menimbulkan subluksasi lutut dan fiksasi profilaksis sendi lutut dengan mobile binge dapat dilakukan dengan peralatan Ilizarov. (Stanitski ,1999)

Dislokasi posterior tibia dapat ditarik ke anterior perlahan dengan mobile Ilizarov binge on a rail untuk mengurangi dislokasi dan memperkenankan gerakan sendi lutut.. Pada subluksasi hip, traksi dan istirahat cukup sudah mencukupi. (Stanitski 1999)

\section{E.4 Masalah Neurovaskular}

Komplikasi neurovascular sering berhubungan dengan kesalahan penempatan pin, tetapi dapat juga diakibatkan stretching selama pemanjangan. Jika distraksi $1 \mathrm{~mm} /$ hari, jaringan neurovascular hampir selalu bias meregang mengikuti pemanjangan. Jika saraf cutaneus tertarik di atas wire/ pin, maka pin harus diambil. (Stanitski ,1999)

Disfungsi saraf peroneus terjadi pada pemanjangan tibia yang harus diterapi dengan nerve decompression pada kaput fibula, diperpanjang ke proximal 5-7 cm dan ke distal sampai ke kompartemen anterior. (Stanitski, 1999)

\section{E.5 Masalah Tulang}

Masalah tulang pada distraction osteogenesis termasuk konsolidasi premature dan konsolidasi yang tertunda. Pada pemanjangan metode Wagner masalah tersering adalah infeksi, pseudoarthrosis, plate patah dan malunion. Dengan distraction osteogenesis oleh Ilizarov maupun DeBastiani, konsolidasi premature atau tertunda dapat diatasi tanpa mempengaruhi hasil akhir. (Stanitski ,1999)

Konsolidasi premature disebabkan periode laten yang memanjang. Untuk pemanjangan femur pada anak, periode laten 5 hari, dan untuk pemanjangan tibia 7 hari. Untuk pasien yang lebih tua dengan permasalahan vaskuler pada tungkai, 


\section{Vol. 10 No.1 Tahun 2014}

periode laten diperpanjang. Konsolidasi premature dari fibula pada pemanjangan tibia dapat dicegah dengan menggunakan standar open osteotomy fibula daripada kortikotomi. (Stanitski ,1999)

Konsolidasi tertunda paling sering terjadi pada pemanjangan diafisis daripada metafisis kortikotomi. Faktor yang mempengaruhi adalah instabilitas frame, kortikotomi yang terlalu berlebihan dengan stripping periosteal yang berlebihan dan kecepatan distraksi yang terlalu cepat, terutama setelah periode laten yang sangat singkat. Patahan gigli saw pada korteks tulang diafisis dapat menunda penulangan. Penyakit atau masalah nutrisi yang menyertai dan kurang berolahraga memiliki kontribusi penundaan konsolidasi. Untuk mengatasi masalah tersebut, distraksi harus perlahan atau di hentikan, dan dilakukan kompresi tulang. Penggunaan bone graft autolog dapat menjadi solusi untuk menutupi gap yang terjadi. (Stanitski ,1999)

\section{DAFTAR PUSTAKA}

Campbell et al. Campbell's Operative Orthopaedics, 11th ed. Philladhelphia-Pennysilvania. 2007

DeBastiani et al: Limb lengthening by callus distraction (callotasis). J Pediatr Orthop

1987 ; 7 : 1299.

Giles et al. Low back pain associated with leg length inequality. Spine 1981;6:510.

Huurman et al : Limb-length discrepancy measured with computerized axial tomographic equipment. J Bone Joint Surg 1987; 69A:699.

Kristiansen et al.: No difference in tibial lengthening index by use of Taylor spatial frame or Ilizarov external fixator. Acta Orthop
$\begin{array}{lllll}2 & 0 & 0 & 6 & \text {; }\end{array}$
$7 \quad 7: 772$.

Morissy, et al. Lovel \& Winter Pediatric Orthopaedics, $6^{\text {th }}$ edition. Lippincott Williams \& Wilkins, 2006.

Millis et al : Transiliac lengthening of the lower extremity: a modified innominate

osteotomy for the treatment of postural imbalance. J Bone Joint Surg 1979; 61A:1182.

Papaioannou et al. Scoliosis associated with limblength inequality. $J$ Bone Joint Surg $1982 ; 64$ A : 59 .

Paley D et al: Ilizarov treatment of tibial nonunions with bone loss, Clin Orthop Relat Res 241:146,

1989

Stanitski DF: Limb-length inequality: assessment and treatment options. $J A m$ Acad Orthop Surg

1999; 7:143.

Solomon L et al. Apley's system of orthopaedics and fractures, $8^{\text {rd }}$ Ed. Oxford University Press Inc 2001.

Wagner H: Operative lengthening of the femur. Clin Orthop Relat Res 1978; 136:125. 